\title{
Copper-catalyzed Oxidative Trifluoromethylation of Terminal Alkenes Using $\mathrm{AgCF}_{3}$
}

Yukiko Karuo, Tatsuto Hayashi, Atsushi Tarui, Kazuyuki Sato, Kentaro Kawai, Masaaki Omote* Faculty of Pharmaceutical Sciences, Setsunan University 45-1, Nagaotoge-cho, Hirakata, Osaka 573-0101, Japan

\section{Supporting Information}

${ }^{1} \mathrm{H}$ and ${ }^{13} \mathrm{C}$ NMR Charts S2-15 


\section{${ }^{1} \mathrm{H}$ and ${ }^{13} \mathrm{C}$ NMR Charts}

\section{4-((E)-4,4,4-Trifluorobut-1-ene-1-yl)anisole (2a)}
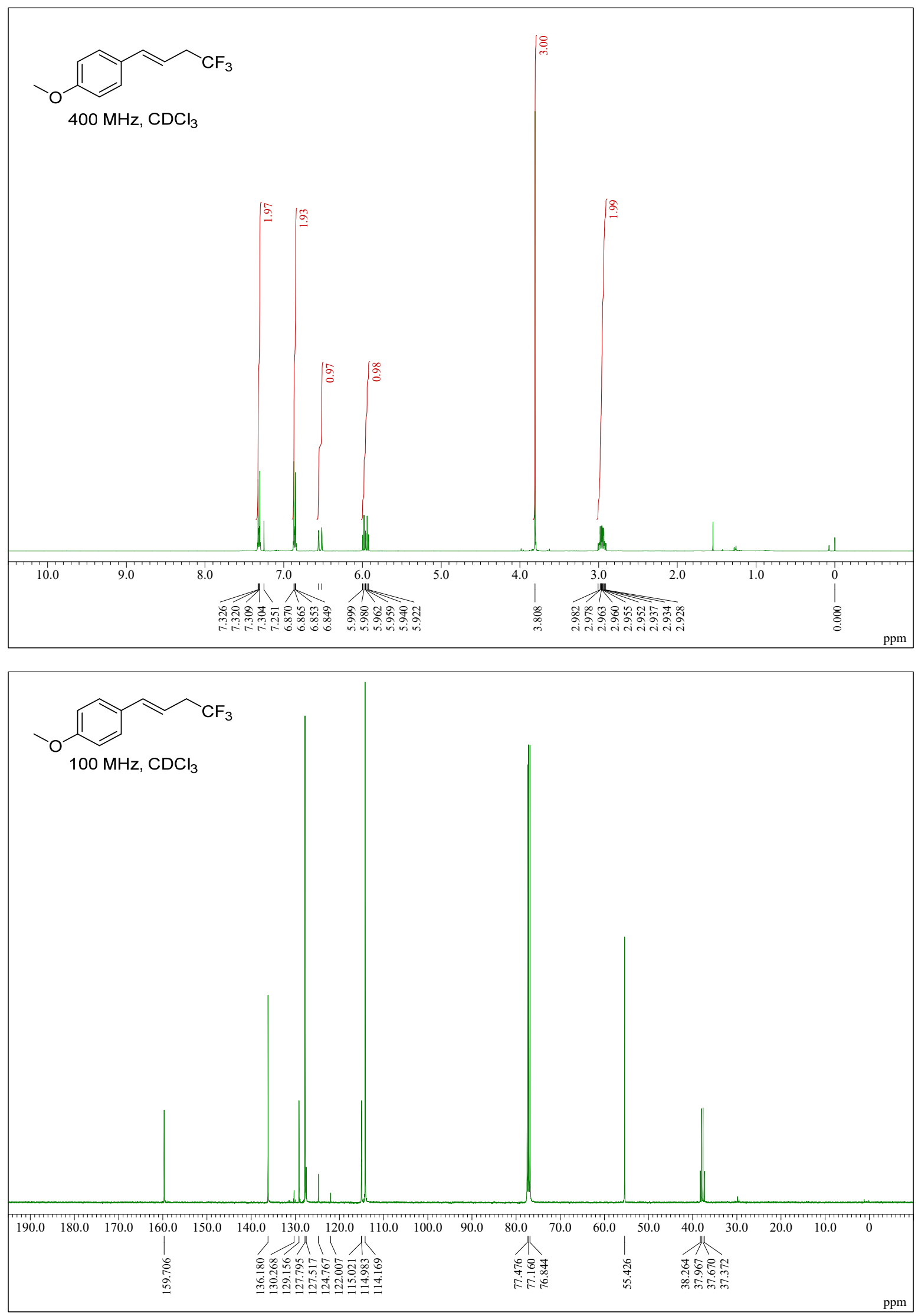
4-((E)-4,4,4-Trifluorobut-1-ene-1-yl)benzene (2b)
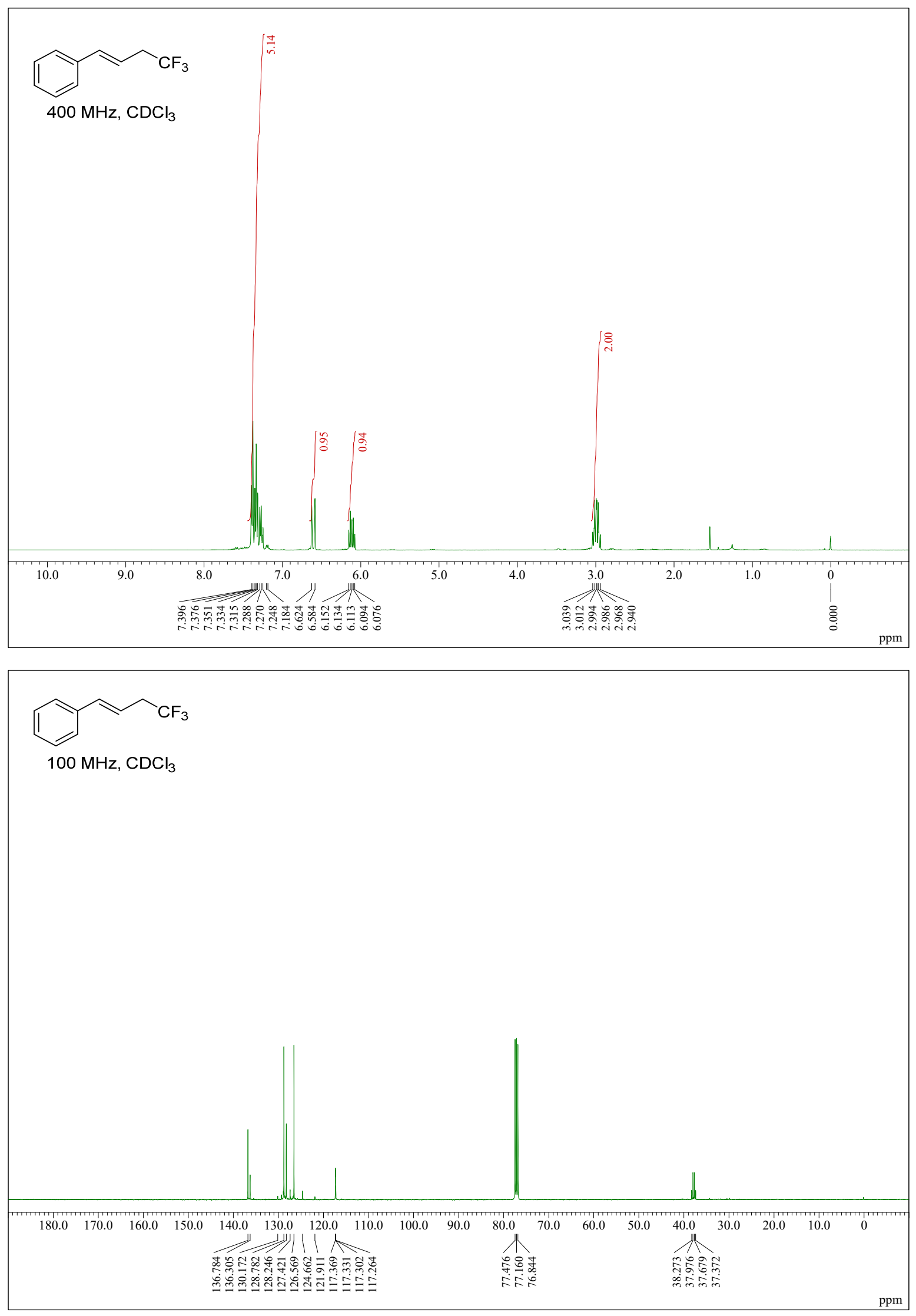


\section{(E)-1,1,1-Trifluoroheptadec-3-ene (2c)}
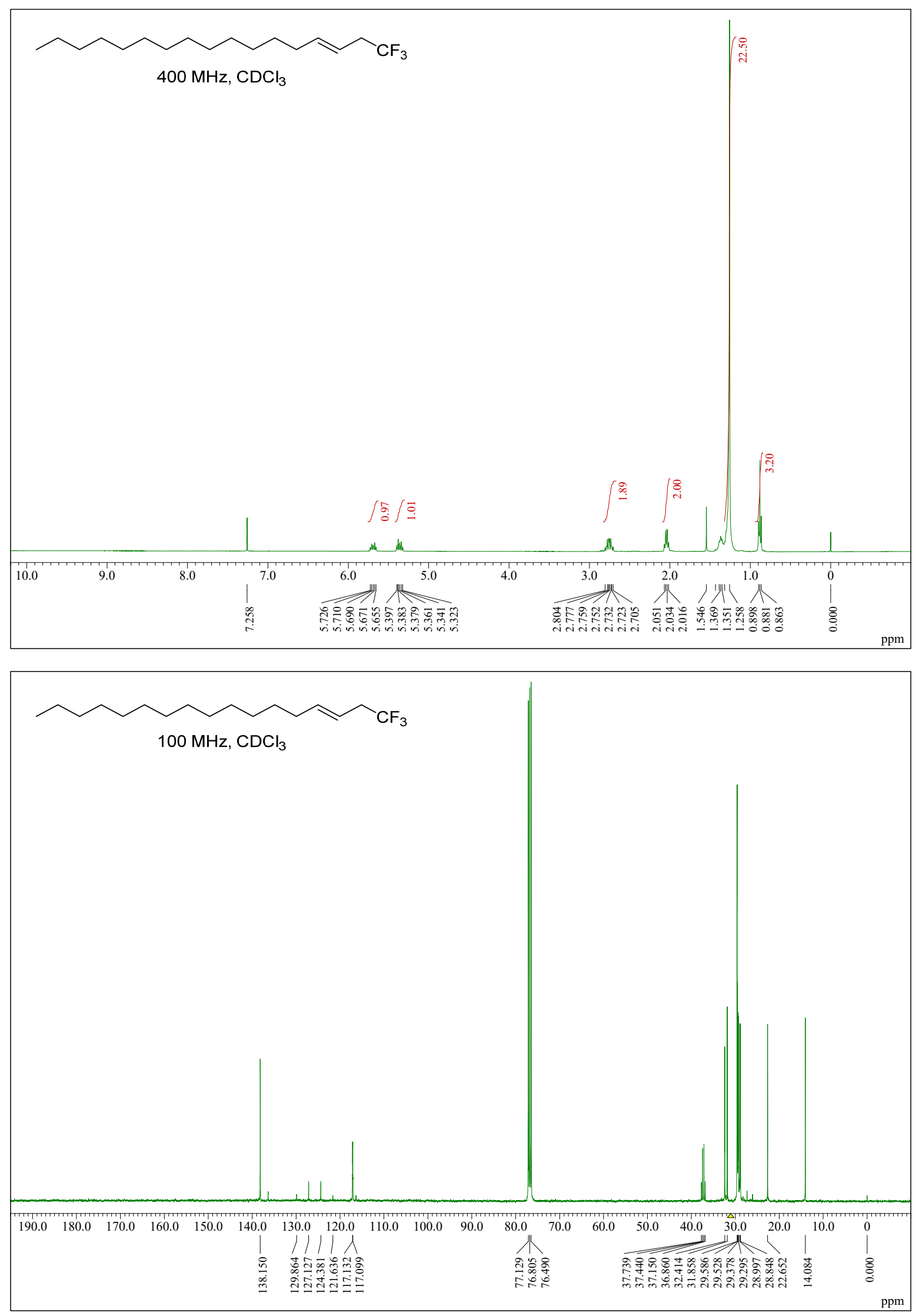

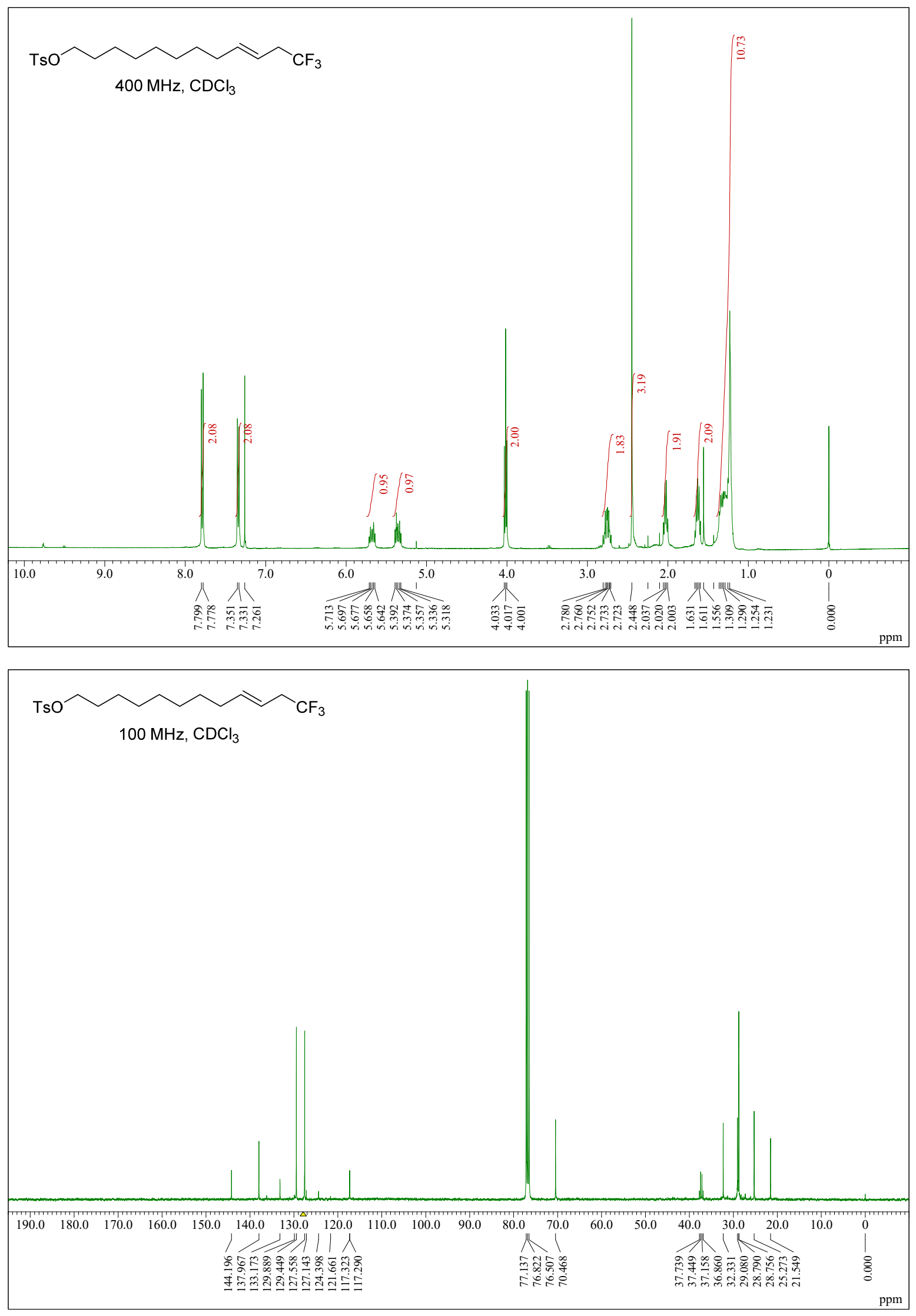


\section{(E)-methyl 12,12,12-trifluorododec-9-enoate (2e)}
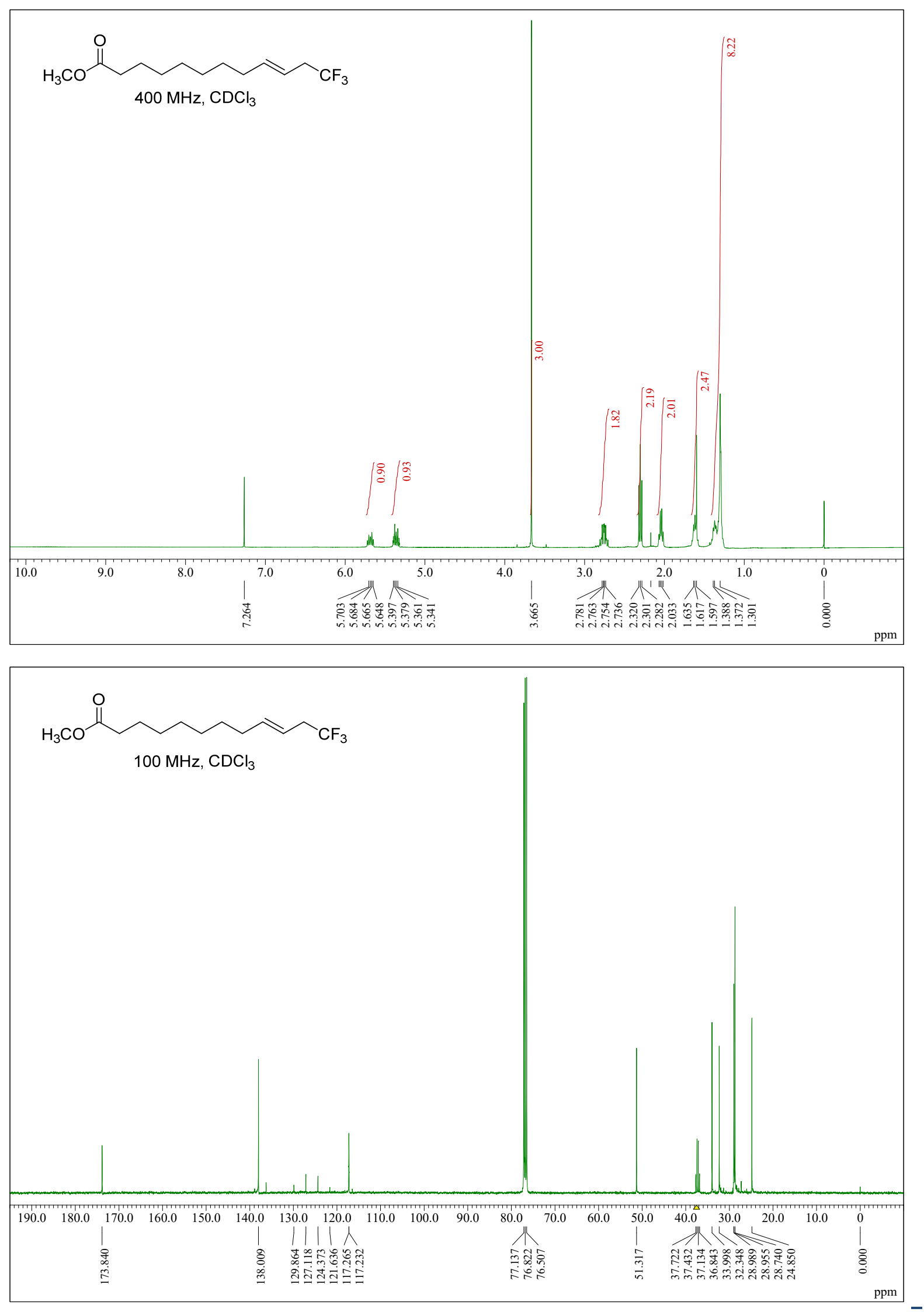

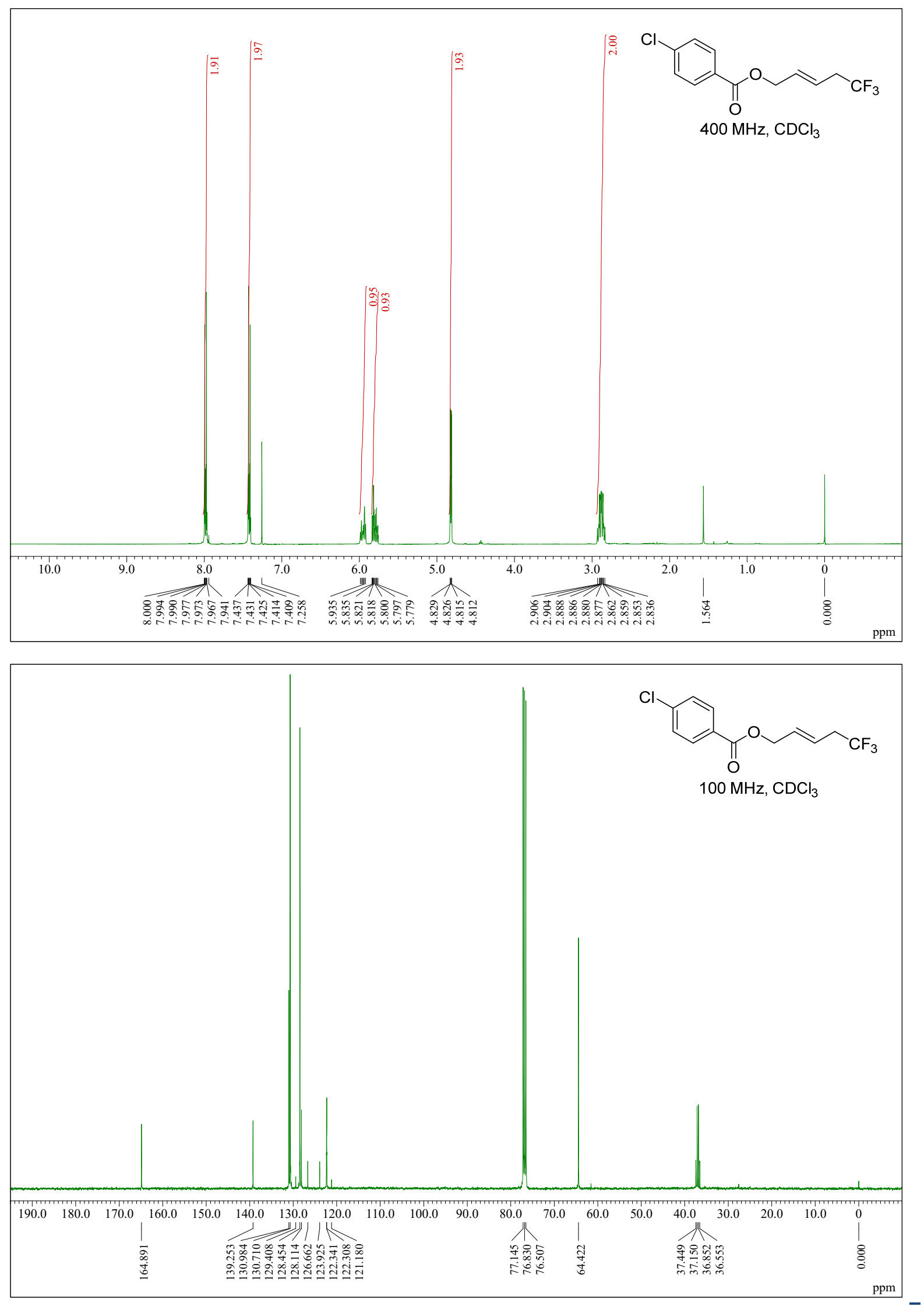


\section{(E)-2-(9,9,9-trifluoronon-6-en-1-yl)oxirane (2g)}
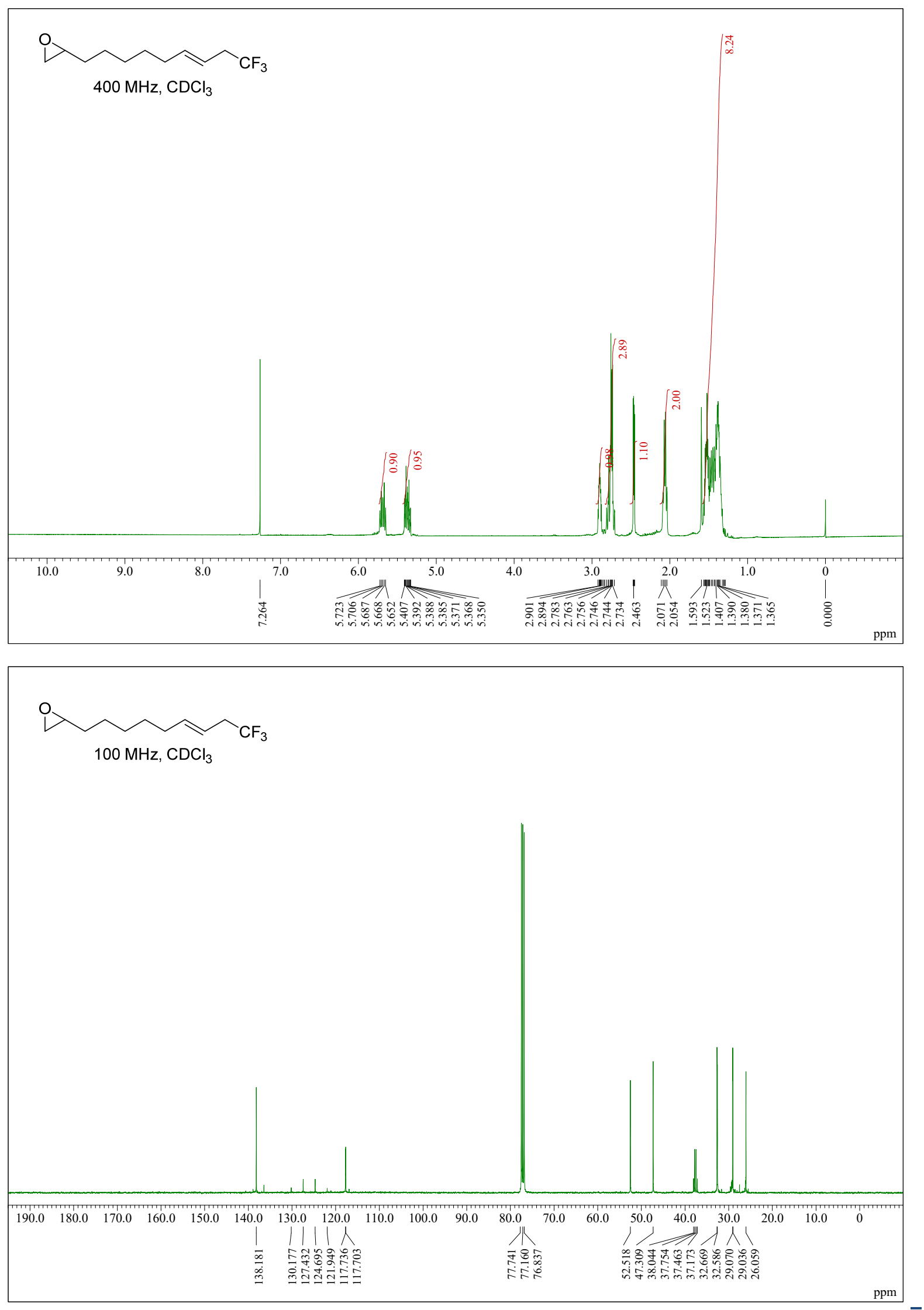

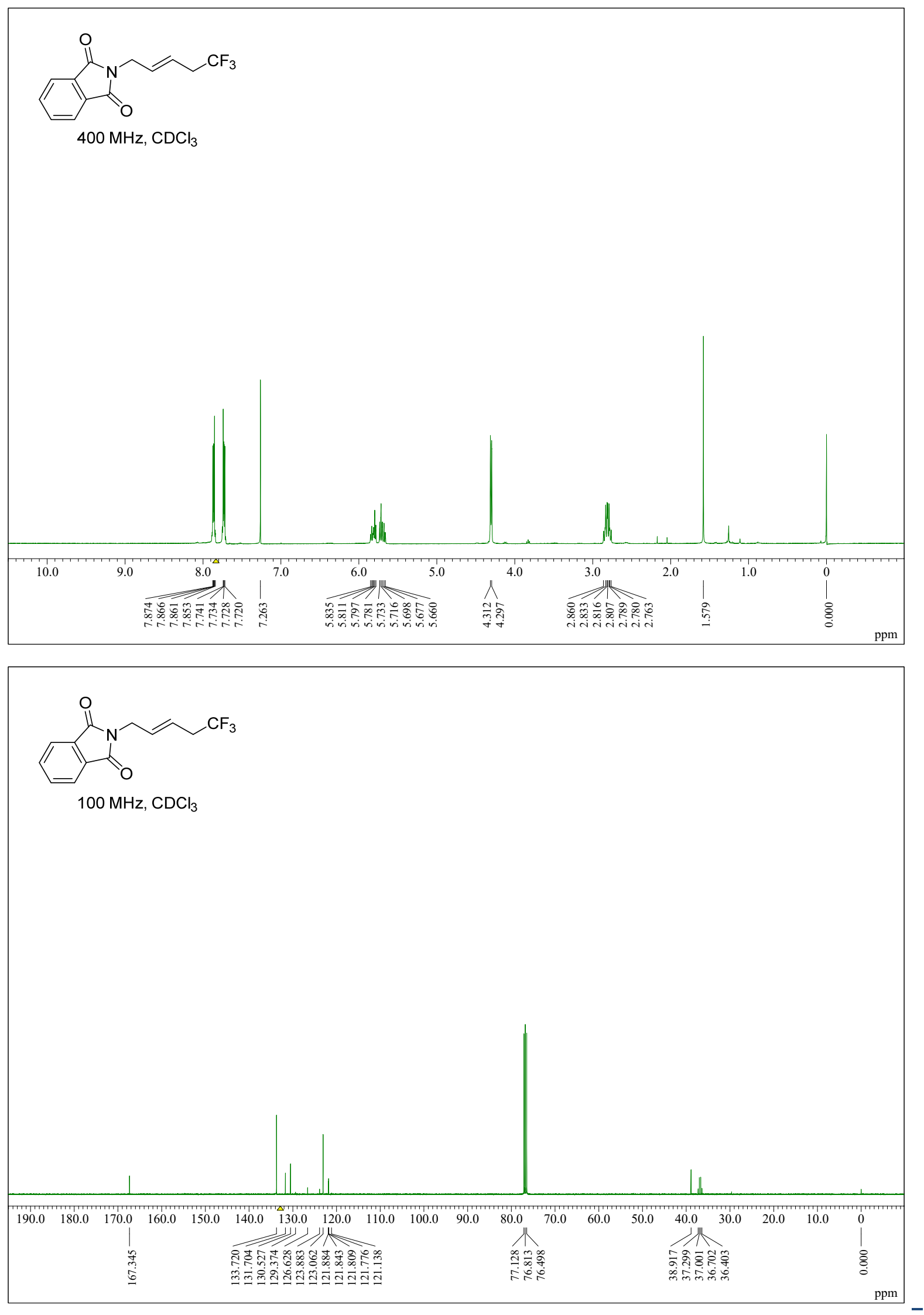
(E)-12,12,12-trifluorododec-9-en-1-ol (2i)
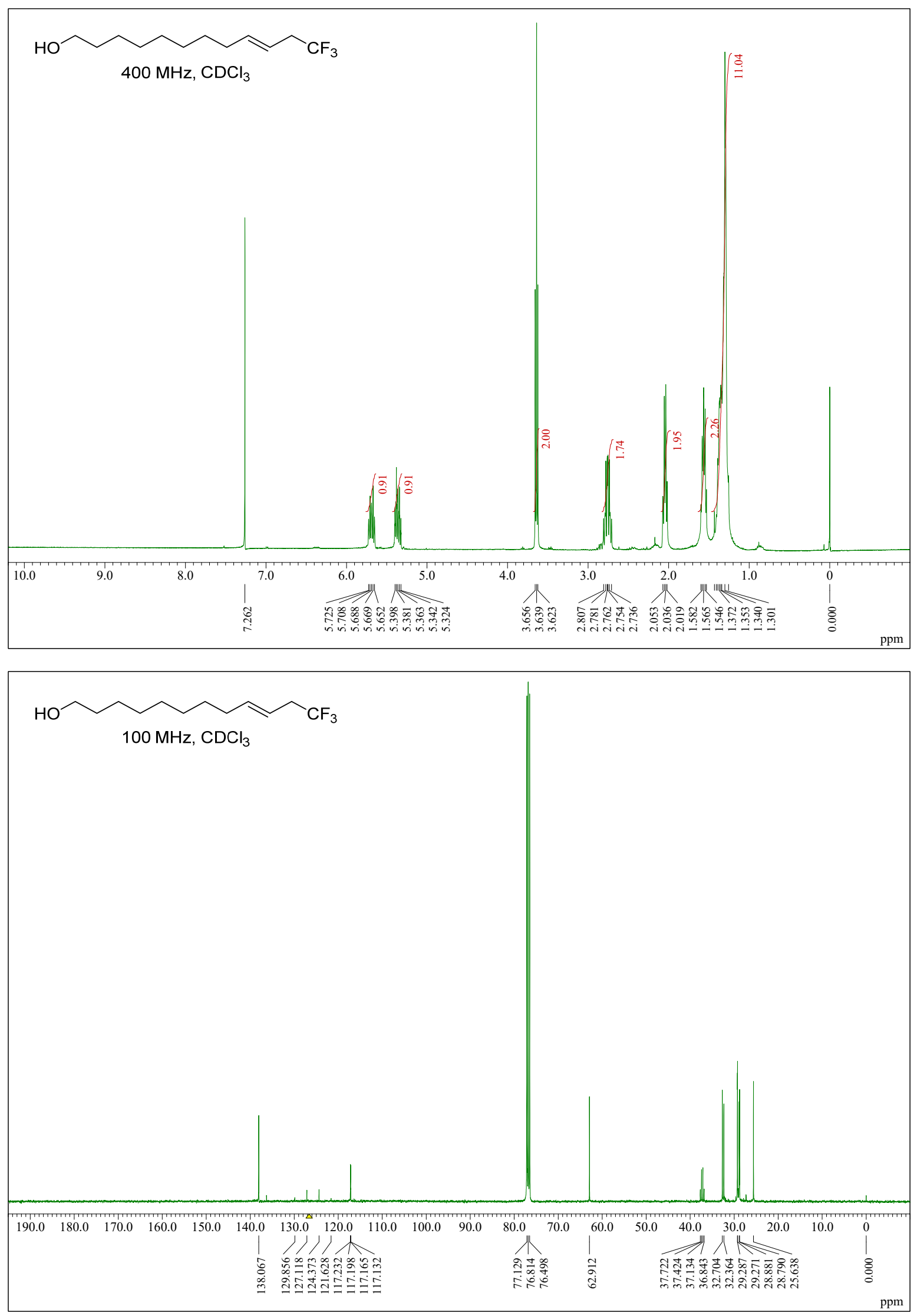


\section{(E)-12,12,12-trifluorododec-9-enal (2i)}
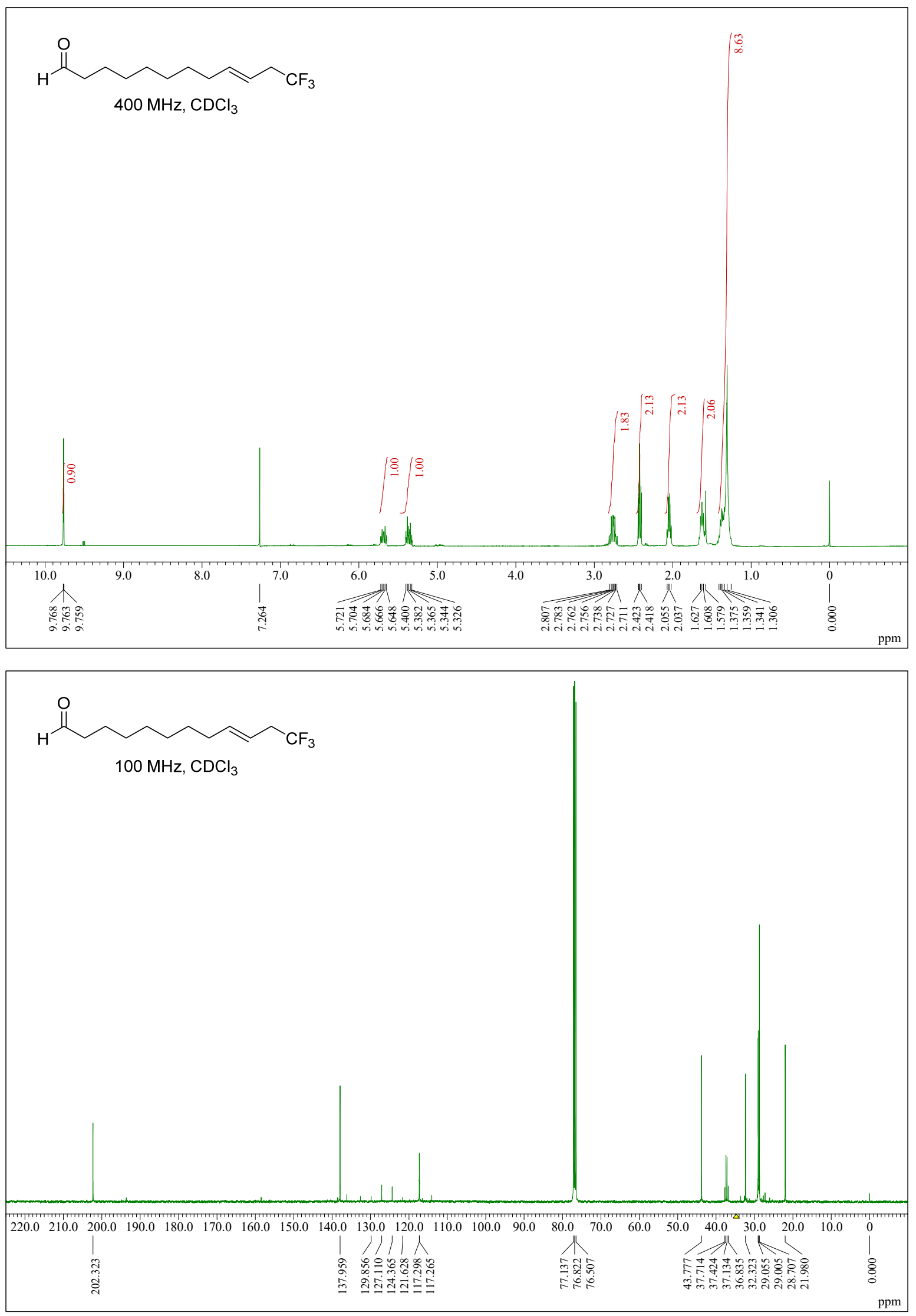


\section{(E)-4-((7,7,7-trifluorohept-4-en-1-vl)oxy)benzaldehyde (2k)}
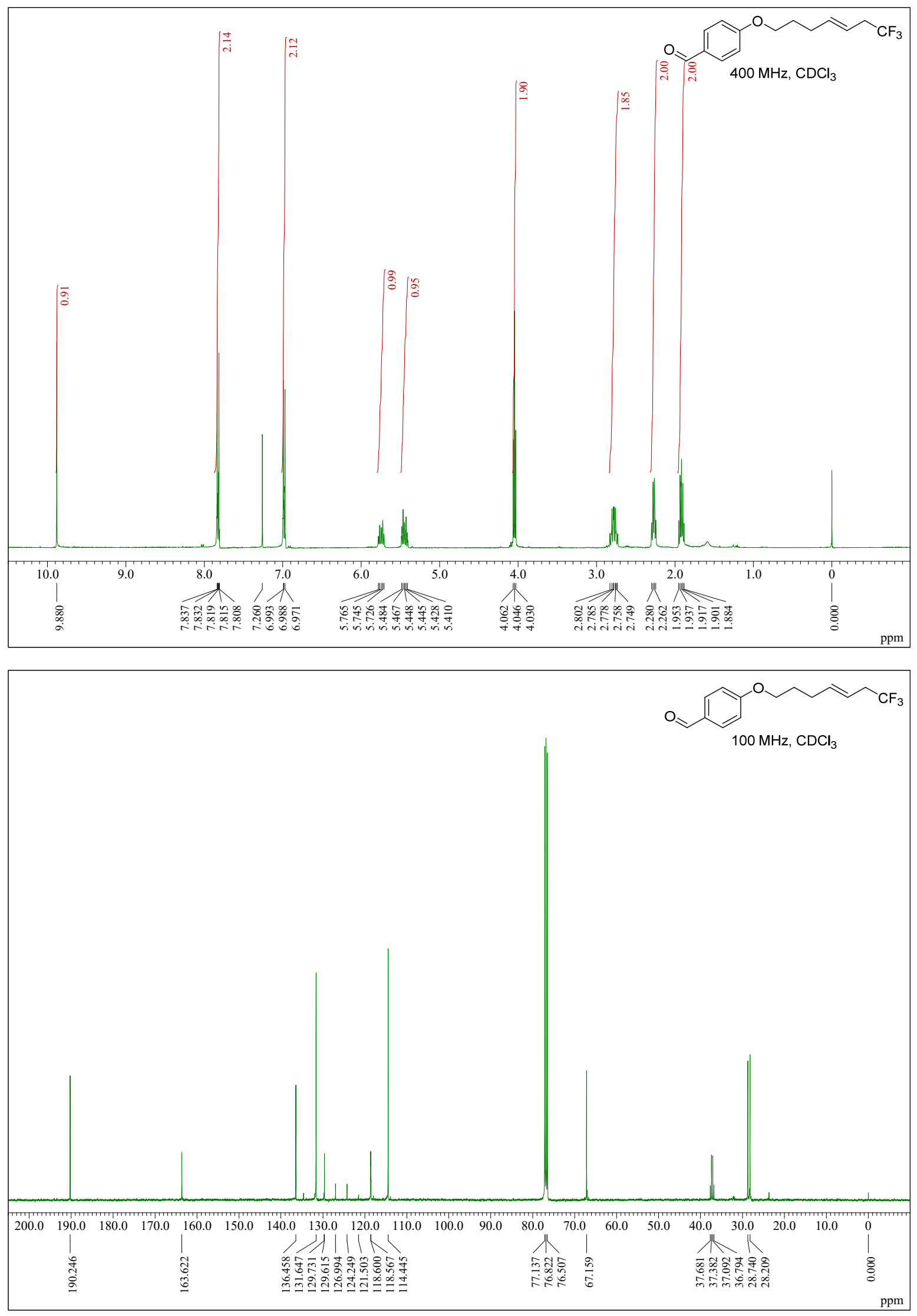

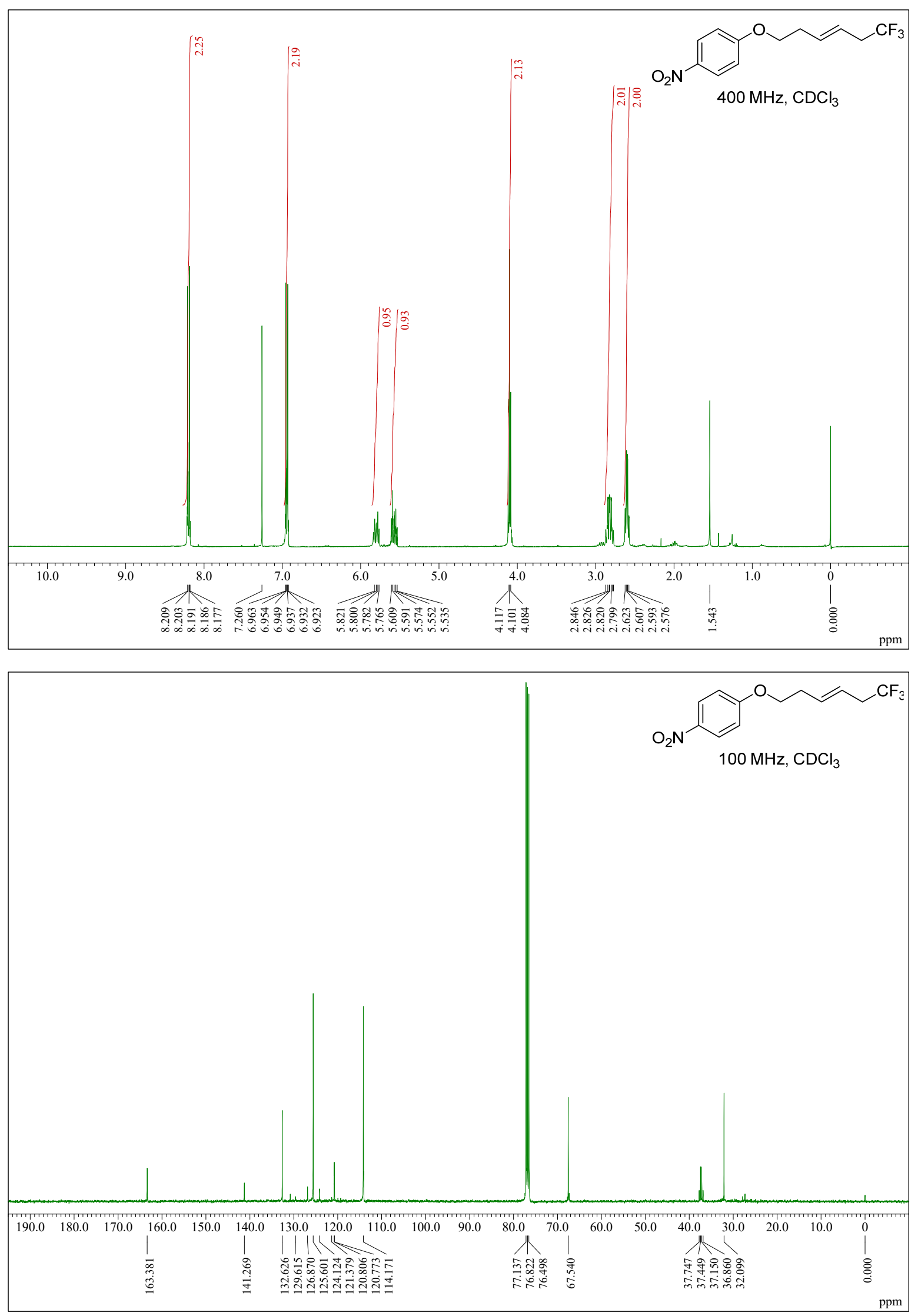

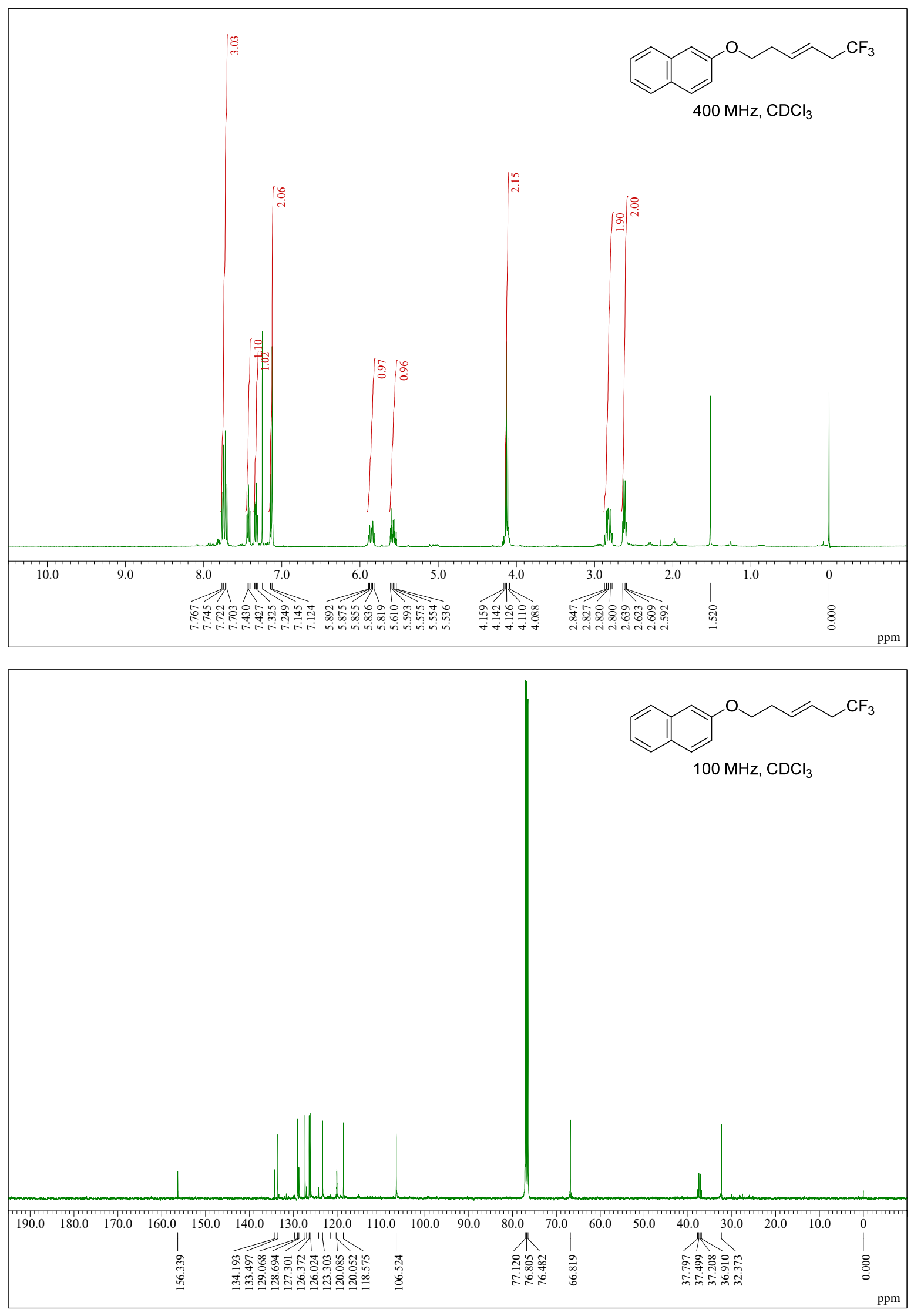
(E)-1-methoxy-4-((6,6,6-trifluorohex-3-en-1-yl)oxy)benzene (2n)
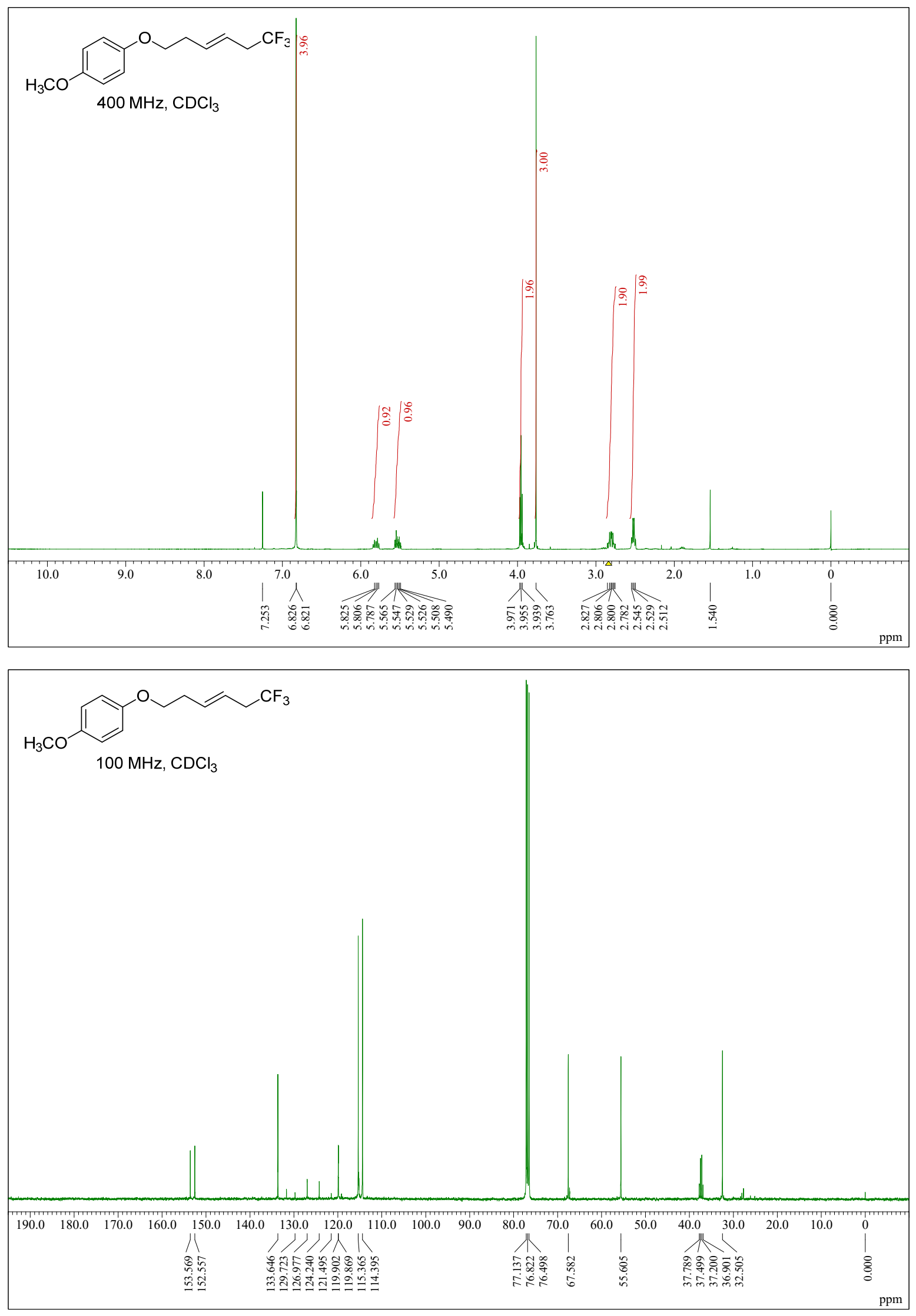